\title{
BROOKHBVEN
}

NATIONAL LABORATORY

BNL-76869-2006-IR

\section{Event Rates for Off Axis NuMI Experiments}

\author{
Brett Viren
}

July 2006

\author{
Physics Department \\ Electronic Detector Group \\ Brookhaven National Laboratory \\ P.O. Box 5000 \\ Upton, NY 11973-5000 \\ www.bnl.gov
}

Notice: This manuscript has been authored by employees of Brookhaven Science Associates, LLC under Contract No. DE-AC02-98CH10886 with the U.S. Department of Energy. The publisher by accepting the manuscript for publication acknowledges that the United States Government retains a non-exclusive, paid-up, irrevocable, world-wide license to publish or reproduce the published form of this manuscript, or allow others to do so, for United States Government purposes. 


\section{DISCLAIMER}

This work was prepared as an account of work sponsored by an agency of the United States Government. Neither the United States Government nor any agency thereof, nor any of their employees, nor any of their contractors, subcontractors or their employees, makes any warranty, express or implied, or assumes any legal liability or responsibility for the accuracy, completeness, or any third party's use or the results of such use of any information, apparatus, product, or process disclosed, or represents that its use would not infringe privately owned rights. Reference herein to any specific commercial product, process, or service by trade name, trademark, manufacturer, or otherwise, does not necessarily constitute or imply its endorsement, recommendation, or favoring by the United States Government or any agency thereof or its contractors or subcontractors. The views and opinions of authors expressed herein do not necessarily state or reflect those of the United States Government or any agency thereof. 


\title{
Event Rates for Off Axis NuMI Experiments
}

\author{
B. Viren, bv@bnl.gov
}

June 8,2006

\begin{abstract}
Neutrino interaction rates for experiments placed off axis in the NuMI beam are calculated. Primary proton beam energy is $120 \mathrm{GeV}$ and four locations at $810 \mathrm{~km}$ from target and $6,12,30$ and $40 \mathrm{~km}$ off axis are considered.
\end{abstract}

\section{Contents}

1 Introduction $\quad 2$

2 Baselines 2

3 Neutrino Flux 2

4 Oscillation Probability 2

5 Cross Sections $\quad 2$

6 Comparison with MINOS Near Detector Data 5

7. Off-axis Event Rates 9 


\section{Introduction}

A generic calculation of neutrino event rates for detectors at various locations in the NuMI neutrino beam has been done. Only flux, probability, cross sections and rudimentary energy reconstruction is considered. No particular detector technology is assumed.

\section{Baselines}

This document gives a calculation of neutrino flux and interaction rates for detectors placed in the various locations in the NuMI beam at $810 \mathrm{~km}$ from the target. Four off-axis locations are considered: $6 \mathrm{~km}$ (7.4 $\mathrm{mrad}), 12 \mathrm{~km}$ (14.8 $\mathrm{mrad}), 30 \mathrm{~km}(37.0 \mathrm{mrad})$ and $40 \mathrm{~km}(49.4 \mathrm{mrad})$.

\section{Neutrino Flux}

Neutrino flux calculations are performed using the GEANT3 based GNUMI simulation program. The proton beam, target, focussing horns, decay tunnel and other elements are models of what is currently in use by MINOS. The locations of the two focusing horns with respect to the target can focus the neutrino parents to produce different spectra. The so called "Low Energy" (LE) ${ }^{1}$ and "pseudo Medium Energy" (pME) tuning are used to confirm the simulation against measured MINOS near detector data while the "Medium Energy" tuning is used for spectra at $810 \mathrm{~km}$ to match. Table 1 summarizes the beam tunings used. In all cases a $120 \mathrm{GeV}$ primary proton beam is used.

\begin{tabular}{|r|r|r|r|r|}
\hline Name & Target $(\mathrm{cm})$ & Horn 2 $(\mathrm{m})$ & Current (kA) & Version \\
\hline LE & -10 & +10 & 182 & v18 \\
pME & -100 & +10 & 197 & v18 \\
ME & -100 & +13 & 182 & v15 \\
\hline
\end{tabular}

Table 1: Summary of Neutrino Flux Spectra. Distances are measured w.r.t. face of horn 1.

Figure 1 shows the $\nu_{\mu}$ spectra for these three beam configurations. Figure 2 shows the four neutrino components of the flux for the ME configuration.

\section{Oscillation Probability}

For this study, the neutrino oscillation parameters that were used are given in Table 2. They were calculated using the program "nuosc" part of libnuosc $++[1]$. This calculation is a full three-neutrino numerical calculation using the Preliminary Reference Earth Model (PREM) [2] for Earth's density. The calculation mode using constant matter densities averaged over the baseline was used. Figure 3 shows the disappearance and appearance probabilities used.

\section{Cross Sections}

The interactions considered are:

- Quasi-elastic (QF) charged current (CC)

- Total charged current

- Neutral current (NC) single $\pi^{0}$ productions $\left(1 \pi^{0}\right)$

\footnotetext{
${ }^{1}$ More properly, MINOS calls this "LE-10"
} 


\section{Flux, numu on-axis at $\mathbf{1 k m}$}

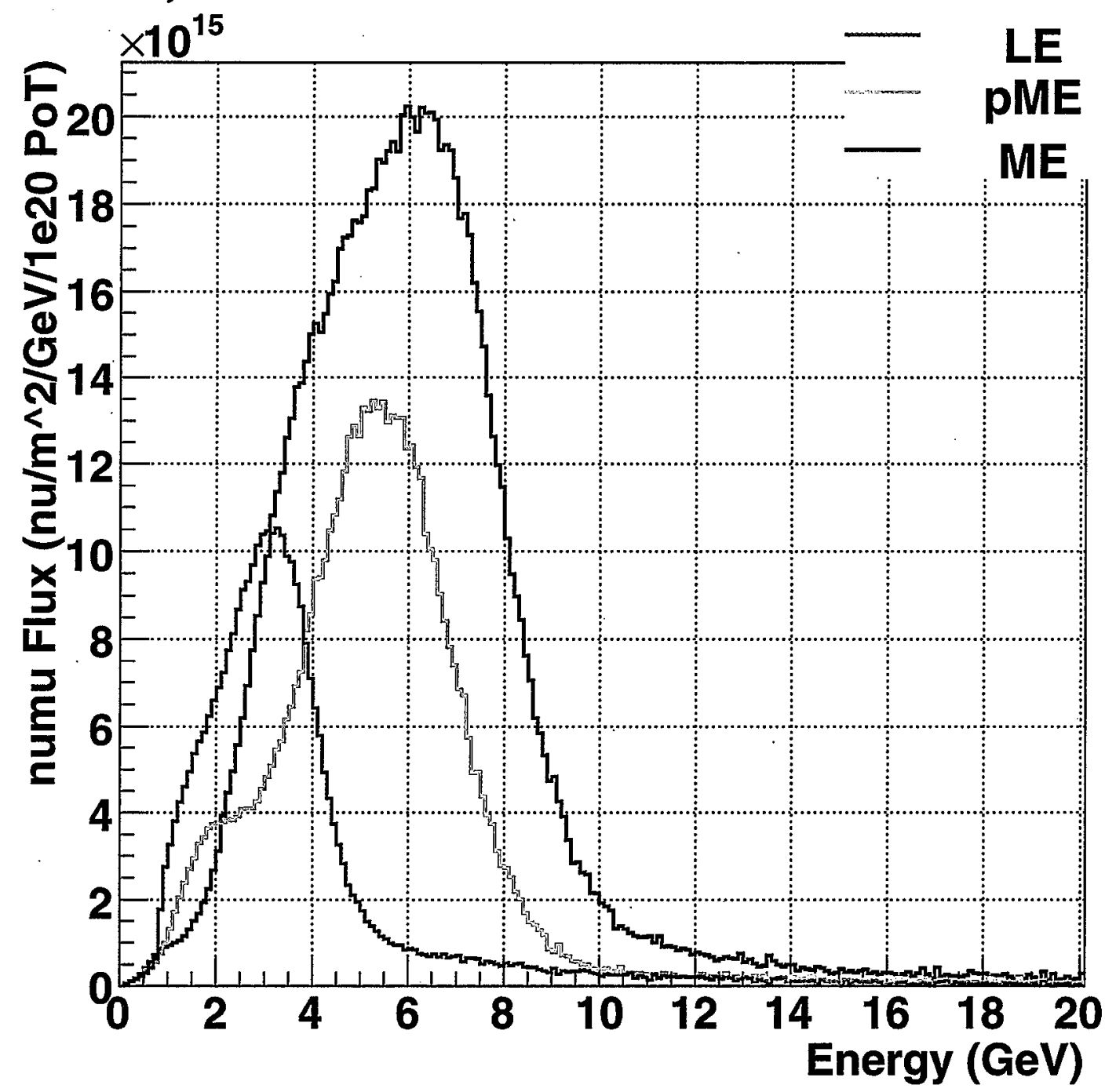

Figure 1: Flux spectra of $\nu_{\mu}$ neutrinos at $1 \mathrm{~km}$ for the beams considered. Note, this is not far flux scaled to $1 \mathrm{~km}$. It contains effects of the secondary beam being an extended source.

\begin{tabular}{|r|r|}
\hline Parameter & Value \\
\hline$\Delta m_{31}^{2}$ & $2.5 \times 10^{-3} \mathrm{eV}^{2}$ \\
$\Delta m_{21}^{2}$ & $8.6 \times 10^{-5} \mathrm{eV}^{2}$ \\
$\sin ^{2} 2 \theta_{12}$ & 0.86 \\
$\sin ^{2} 2 \theta_{23}$ & 1.0 \\
$\sin ^{2} 2 \theta_{13}$ & 0.04 \\
$\delta_{C P}$ & 0 \\
\hline
\end{tabular}

Table 2: Neutrino oscillation parameters used in this study. 


\section{ME Flux components on-axis at $\mathbf{1} \mathbf{k m}$}

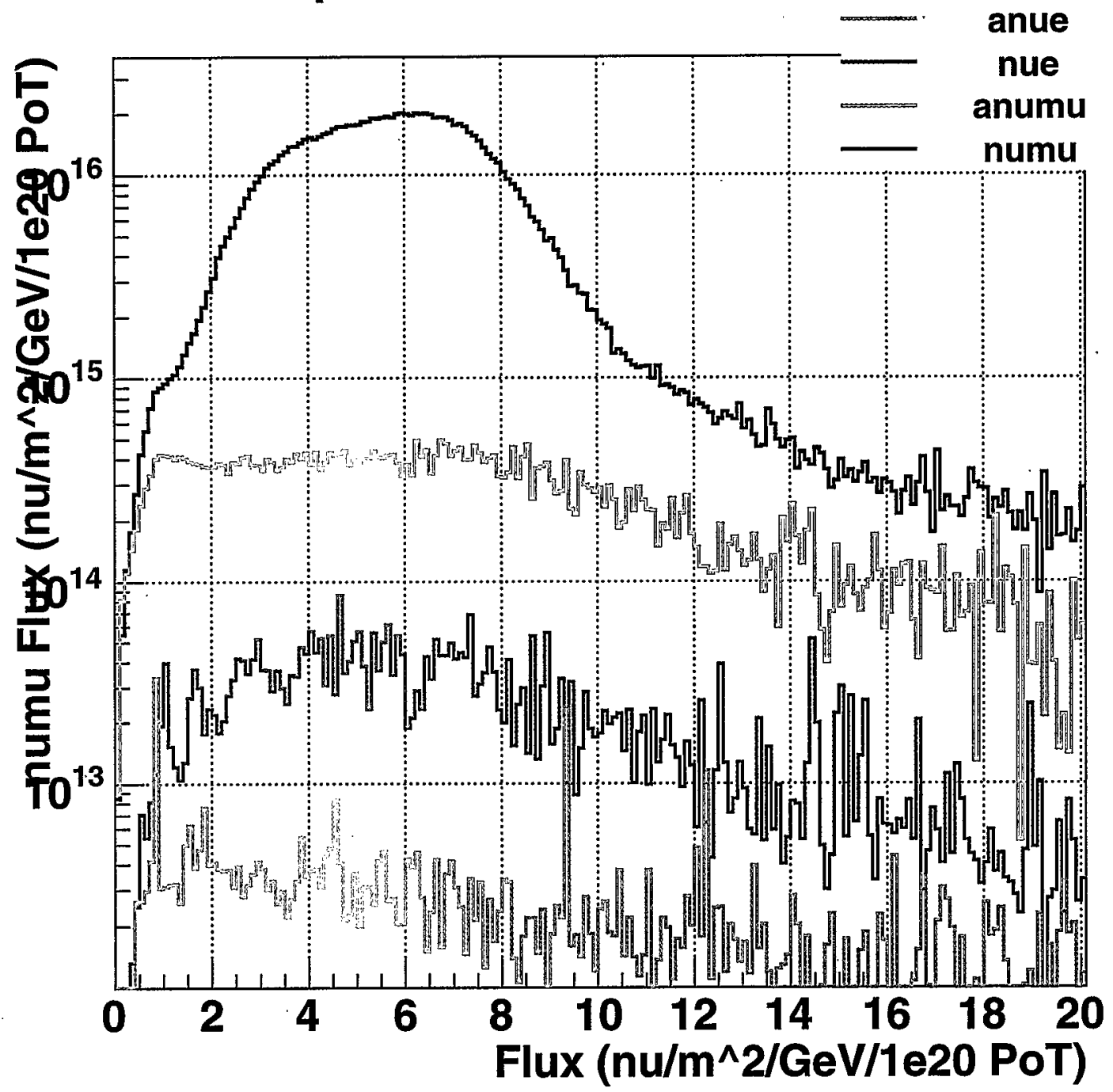

Figure 2: Neutrino flux spectra at $1 \mathrm{~km}$ for the $\mathrm{ME}$ beam. 

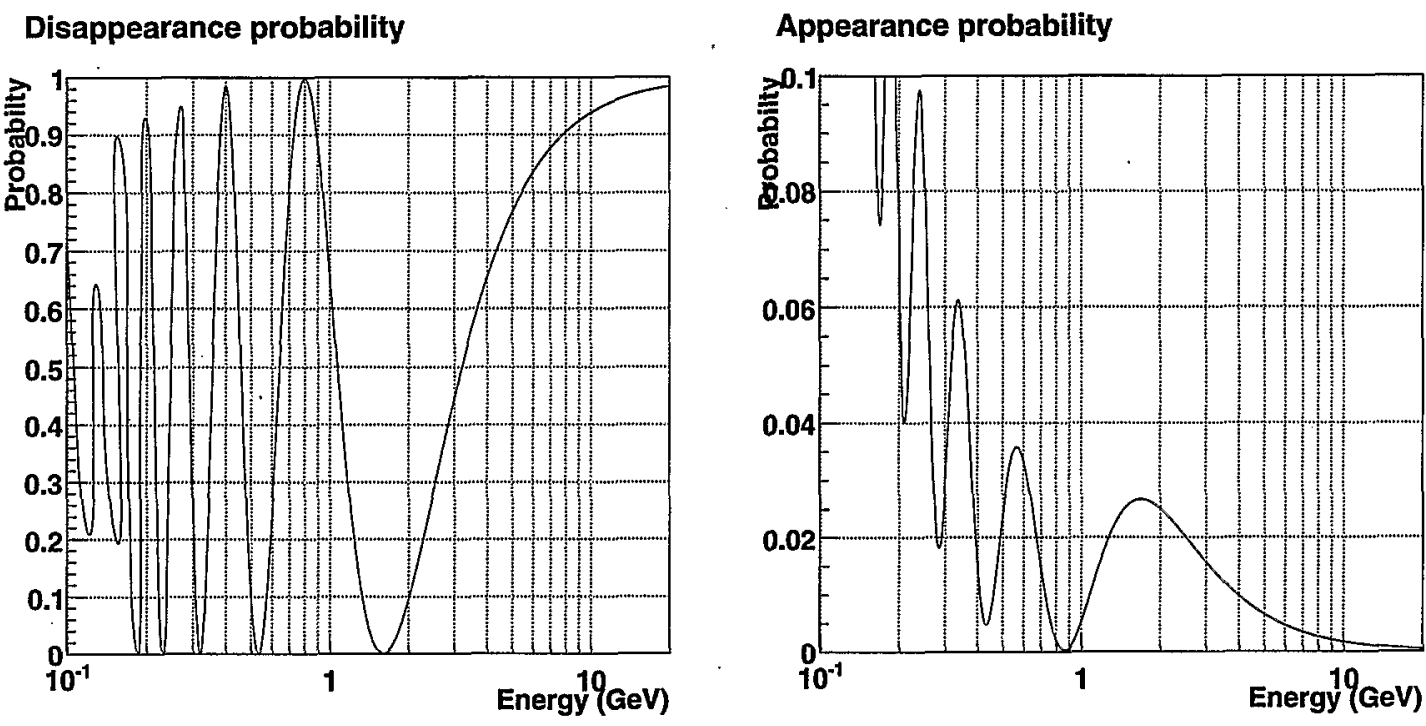

Figure 3: Disappearance (left) and appearance (right) neutrino oscillation probabilities as a function of the neutrino energy. See table 2 for oscillation parameters.

The cross sections used for $\mathrm{QE}$ and $\mathrm{NC}-1 \pi^{0}$ are shown in Figure 4. The total $\mathrm{CC}$ cross sections are parameterized for neutrinos as:

$$
\sigma_{\nu_{\mu}, C C}=0.80 \times 10^{-38} \mathrm{~cm}^{2} / \mathrm{GeV} \times E_{\nu}
$$

and anti-neutrinos as:

$$
\sigma_{\bar{\nu}_{\mu}, C C}=0.35 \times 10^{-38} \mathrm{~cm}^{2} / \mathrm{GeV} \times E_{\nu}
$$

The neutrino energy in charged current (total and $\mathrm{QE}$ ) events is assumed to be reconstructed with perfect energy resolution and with no systematic bias. For NC- $1 \pi^{0}$ events the reconstructed neutrino energy is taken to be the true energy of the $\pi^{0}$ and no consideration for shower angle w.r.t. to the incoming neutrino is made. This produces a softer reconstructed energy spectrum than would be found if this angle were considered. In addition, no account of nuclear absorption nor charge exchange by the $\pi^{0}$ is made.

To simulate the energy of the $\pi^{0}$ sets of $E_{\pi^{0}}$ spectra were generated using mono-energetic neutrinos with energies chosen in steps of $0.5 \mathrm{GeV}$. These were generated with the NUANCE[3] simulation. Figure 5 illustrates this.

All cross sections are applied assuming the detector mass is made up of equal numbers of protons and neutrons.

\section{Comparison with MINOS Near Detector Data}

Figure 6 shows a comparison between GNUMI MC simulation and data collected in the MINOS near detector. There "LE-10" corresponds to the "LE" configuration in this work. The ME simulation used in this work is from a slightly older version (v15) of GNUMI than is used in this comparison (v18). No tuning to the MINOS data has been done and data/MC comparison shows very good agreement. 


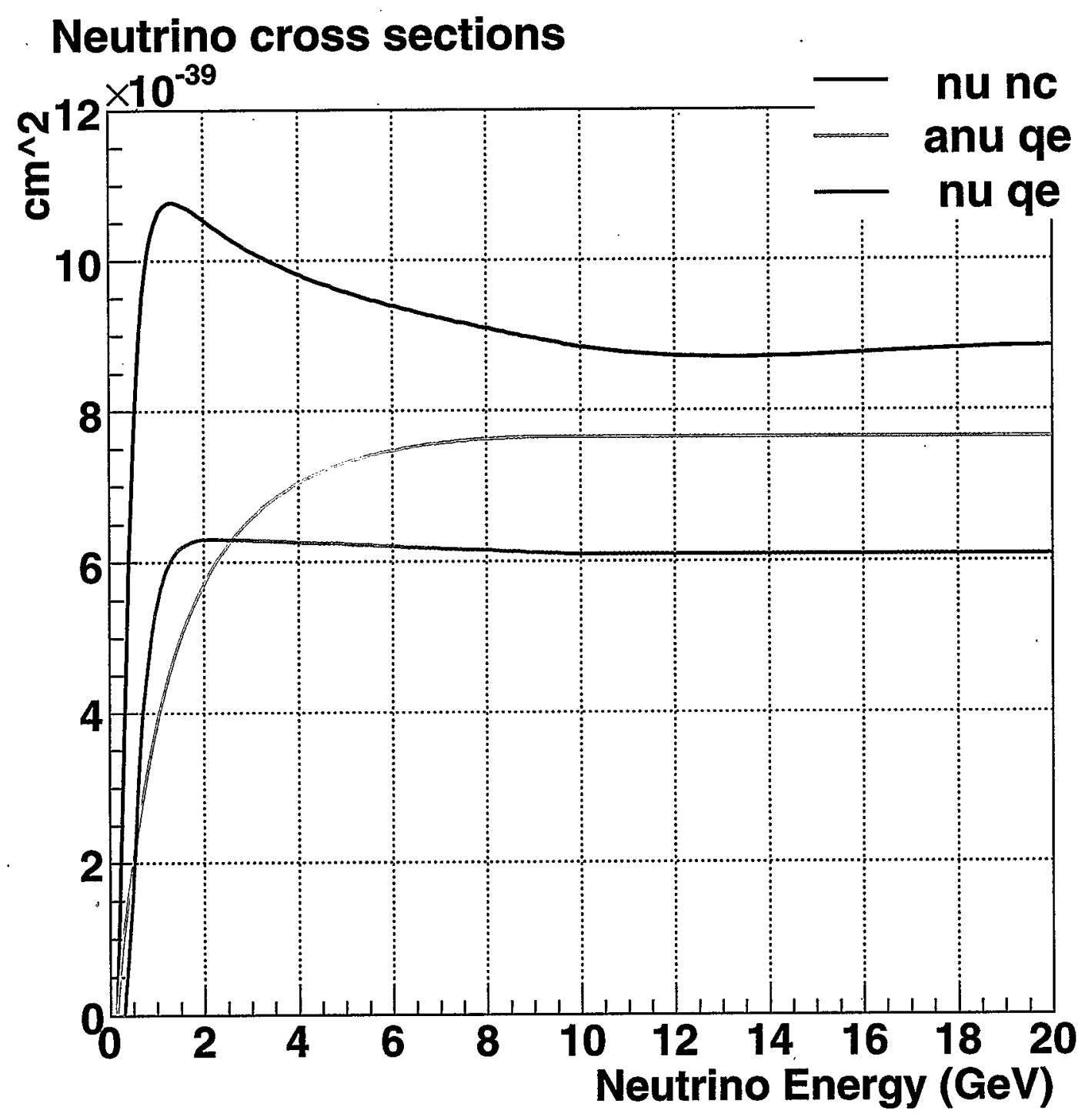

Figure 4: QE and NC- $1 \pi^{0}$ cross sections. 


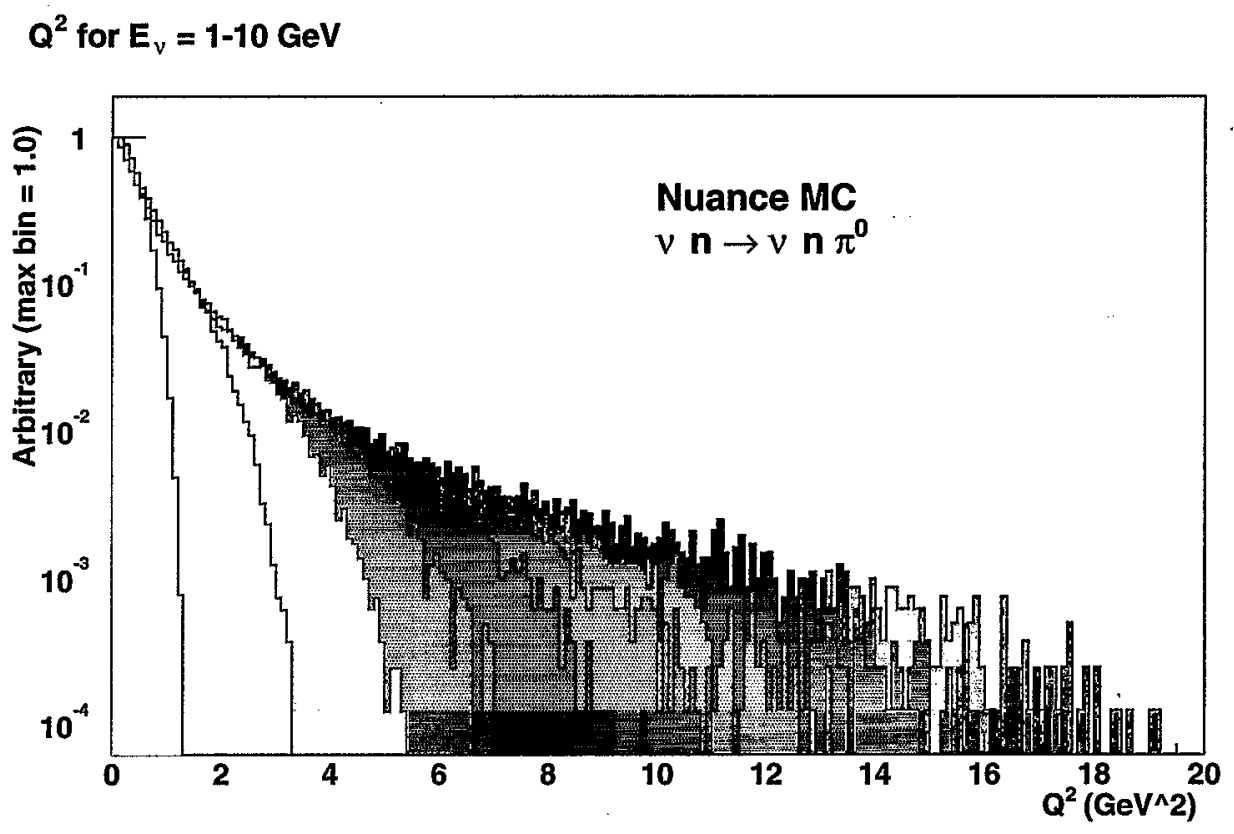

$$
E_{\pi^{0}} \text { for } E_{v}=1-10 \mathrm{GeV}
$$

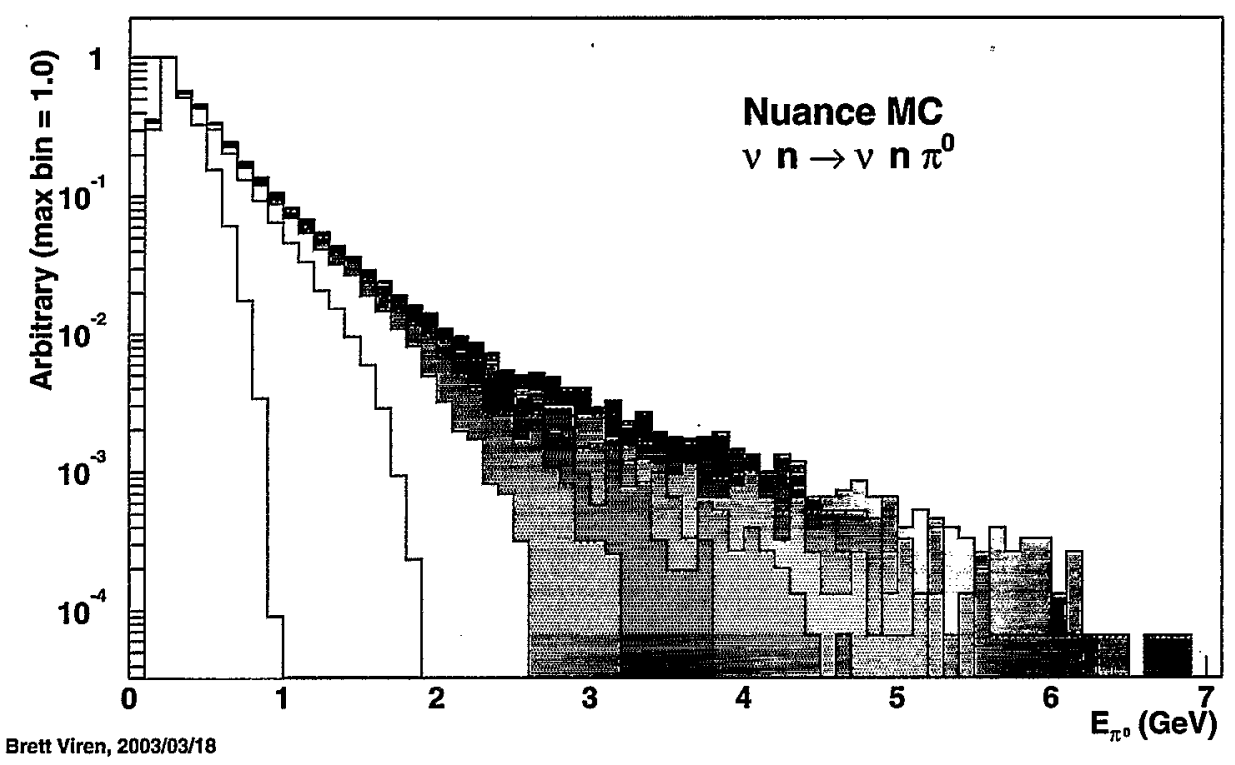

Figure 5: (a) $q^{2}$ (top) and (b) $\pi^{0}$ energy (bottom) as functions of mono-energetic neutrinos in $1 \mathrm{GeV}$ steps. Calculation uses $0.5 \mathrm{GeV}$ steps in neutrino energy. 

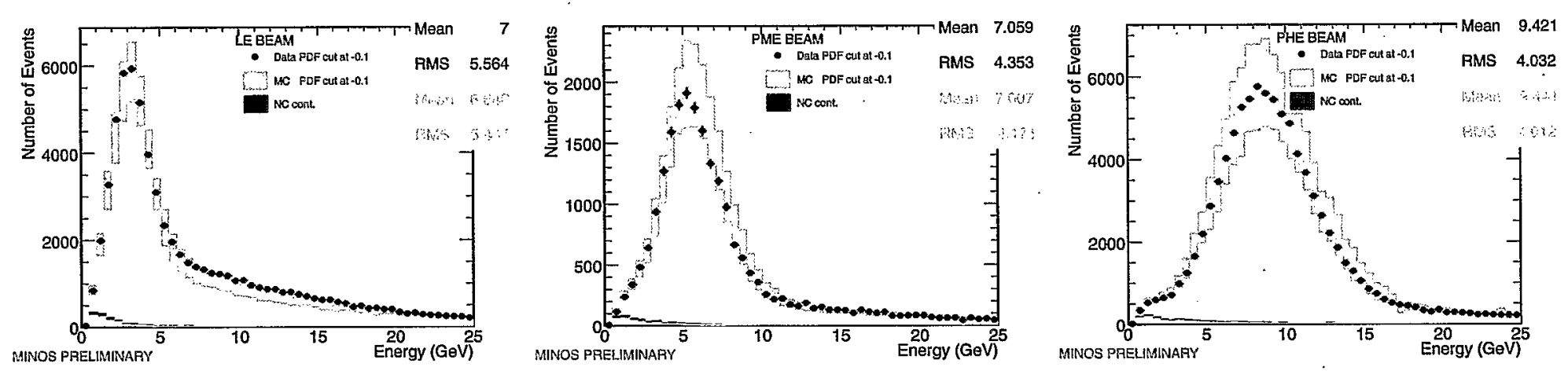

$\infty$
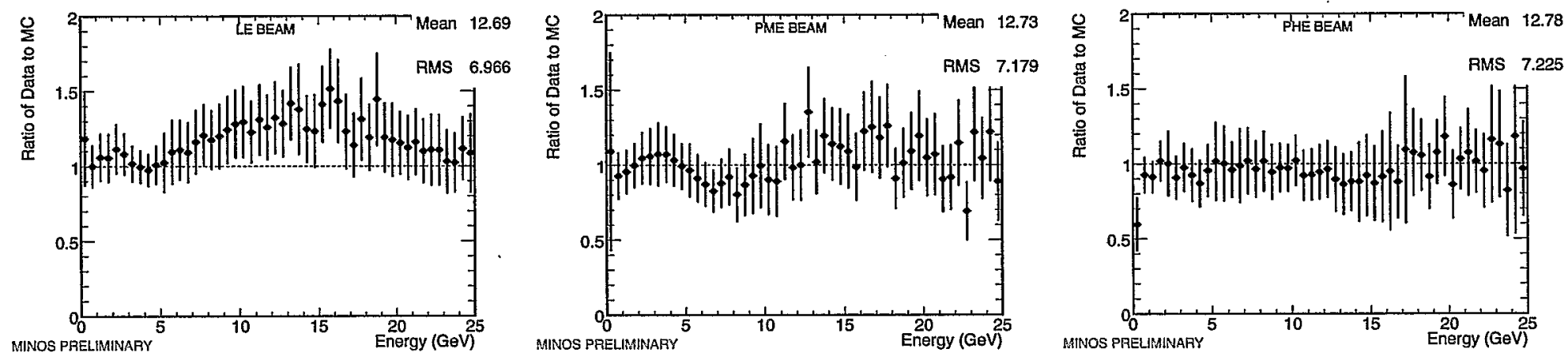

Figure 6: MTNOS Near Detector data and GNUMI MC simulation comparison of interaction spectra[4]. From left, LE, pME and pHE beams. Top row shows data spectra as black points, MC as gray shaded region with a width representing MC uncertainty. Bottom row shows ratio of data to MC. 


\section{Off-axis Event Rates}

All of the above is combined to estimate interaction spectra and rates for disappearance and appearance modes for detectors placed in the NuMI beam. Figures 7-16 show these spectra for an $810 \mathrm{~km}$ baseline at 0 , $6,12,30$ and $40 \mathrm{~km}$ off axis. The event rates are summaries in Table 3 .

\begin{tabular}{|r|c|c|l|l|l|l|l|}
\hline $\mathrm{km}$ o.a. & $\nu_{\mu}$ CC & $\nu_{\mu}$ CC osc & $\nu_{e}$ CC beam & $\nu_{e}$ QE beam & NC-1 $\pi^{0}$ & $\nu_{\mu} \rightarrow \nu_{e}$ CC & $\nu_{\mu} \rightarrow \nu_{e} \mathrm{QE}$ \\
\hline 0 & 248.0 & 225.0 & 1.80 & 0.0914 & 6.96 & 1.40 & 0.188 \\
6 & 71.6 & 47.0 & 1.068 & 0.0770 & 3.194 & 0.879 & 0.171 \\
12 & 18.1 & 7.33 & 0.443 & 0.0485 & 1.168 & 0.305 & 0.099 \\
30 & 1.84 & 1.12 & 0.0730 & 0.0152 & 0.135 & 0.0216 & 0.0108 \\
40 & 0.860 & 0.479 & 0.0378 & 0.0097 & 0.0605 & 0.0121 & 0.0057 \\
\hline
\end{tabular}

Table 3: Summary of event rates per-kTon per- $10^{20}$ PoT for detectors placed $810 \mathrm{~km}$ from the target and various distances off-axis (o.a.). 

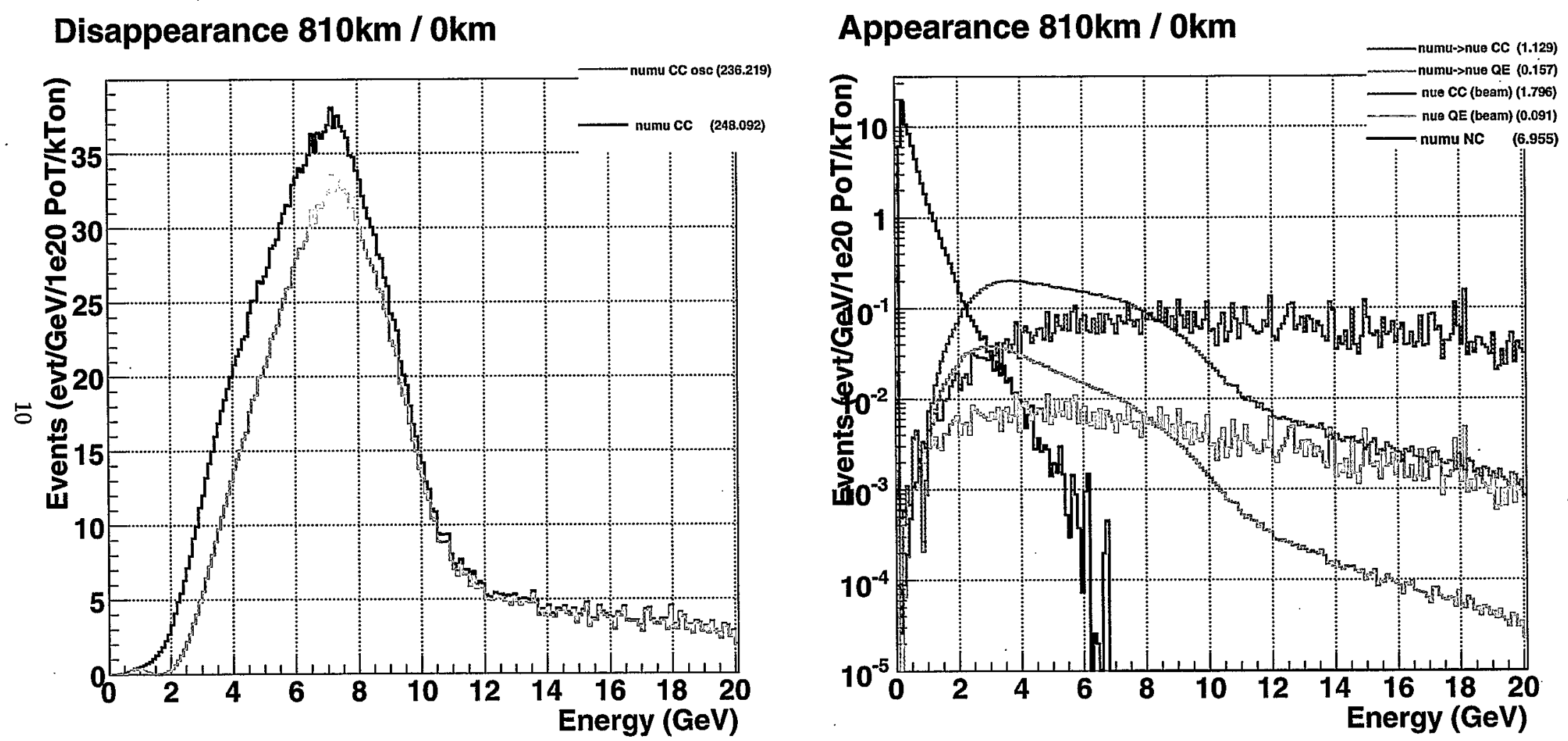

Figure 7: Disappearance (left) and appearance (right) for $810 \mathrm{~km}$ baseline and $0 \mathrm{~km}$ off-axis. 


\section{Disappearance $810 \mathrm{~km} / 0 \mathrm{~km}$}

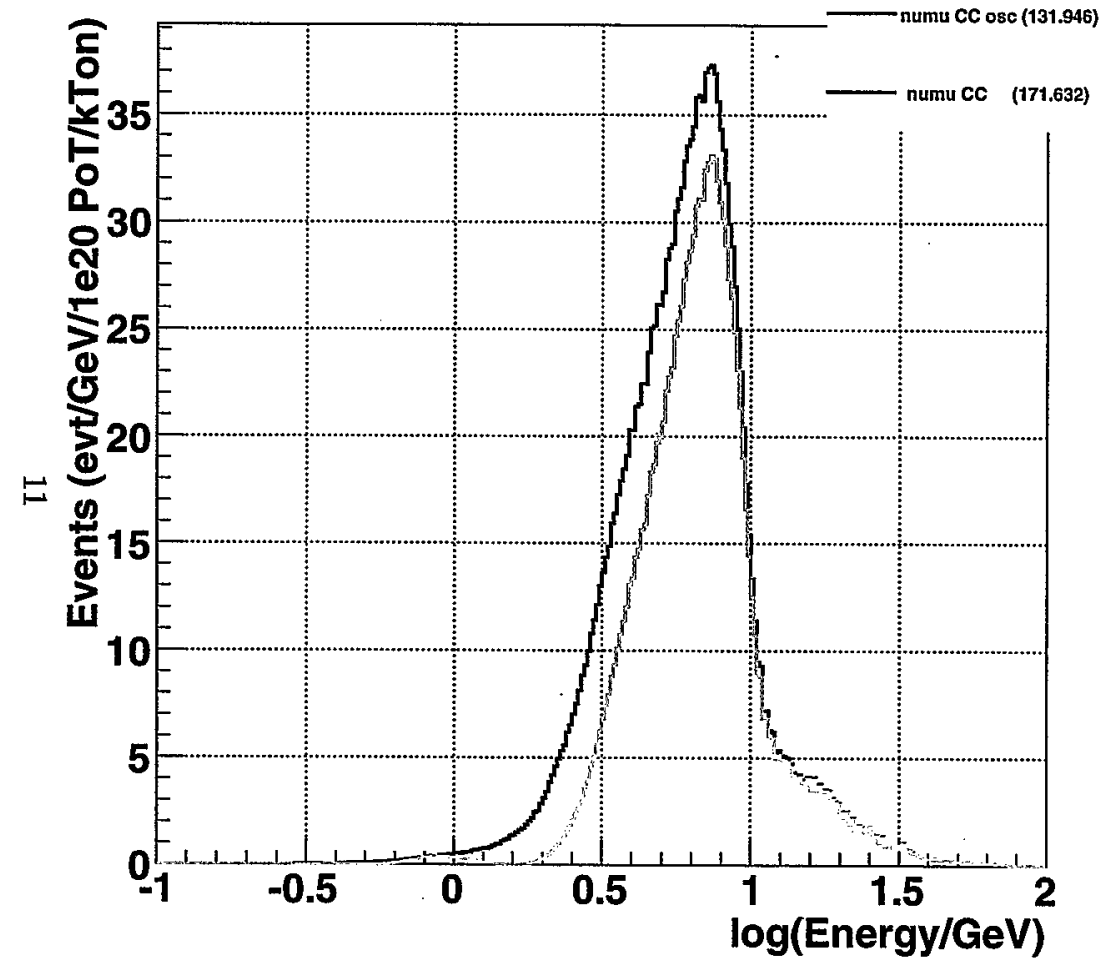

\section{Appearance $810 \mathrm{~km} / 0 \mathrm{~km}$}

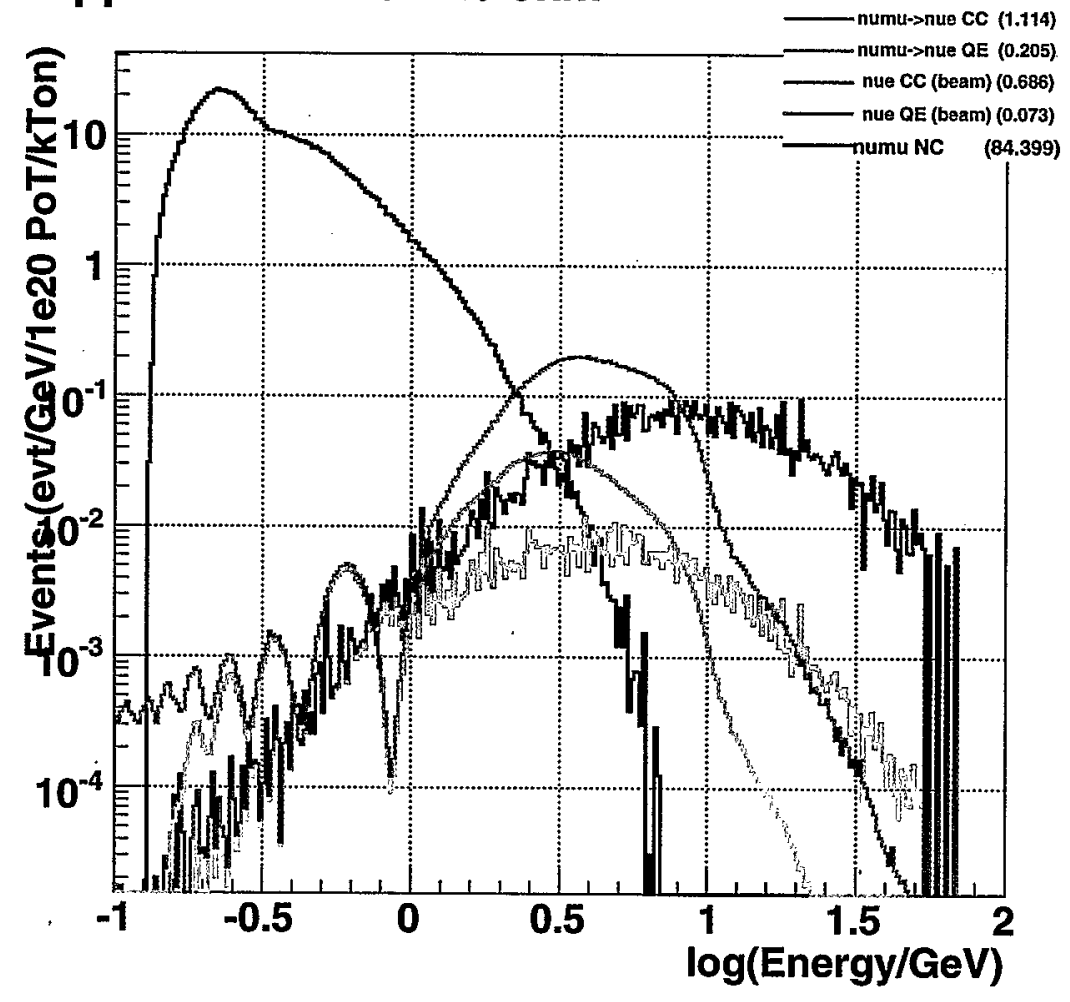

Figure 8: Disappearance (left) and appearance (right) for $810 \mathrm{~km}$ baseline and $0 \mathrm{~km}$ off-axis. 


\section{Disappearance $810 \mathrm{~km} / 6 \mathrm{~km}$}

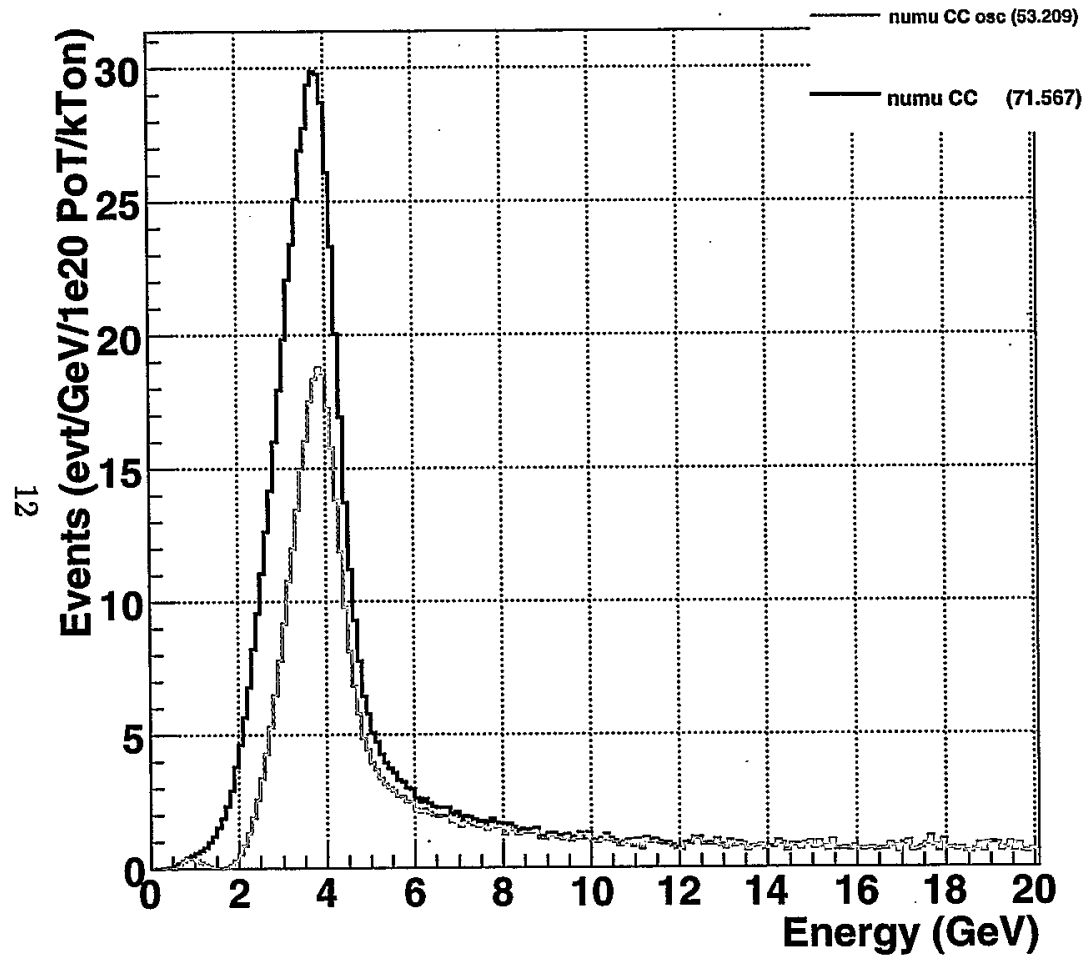

\section{Appearance $810 \mathrm{~km} / 6 \mathrm{~km}$}

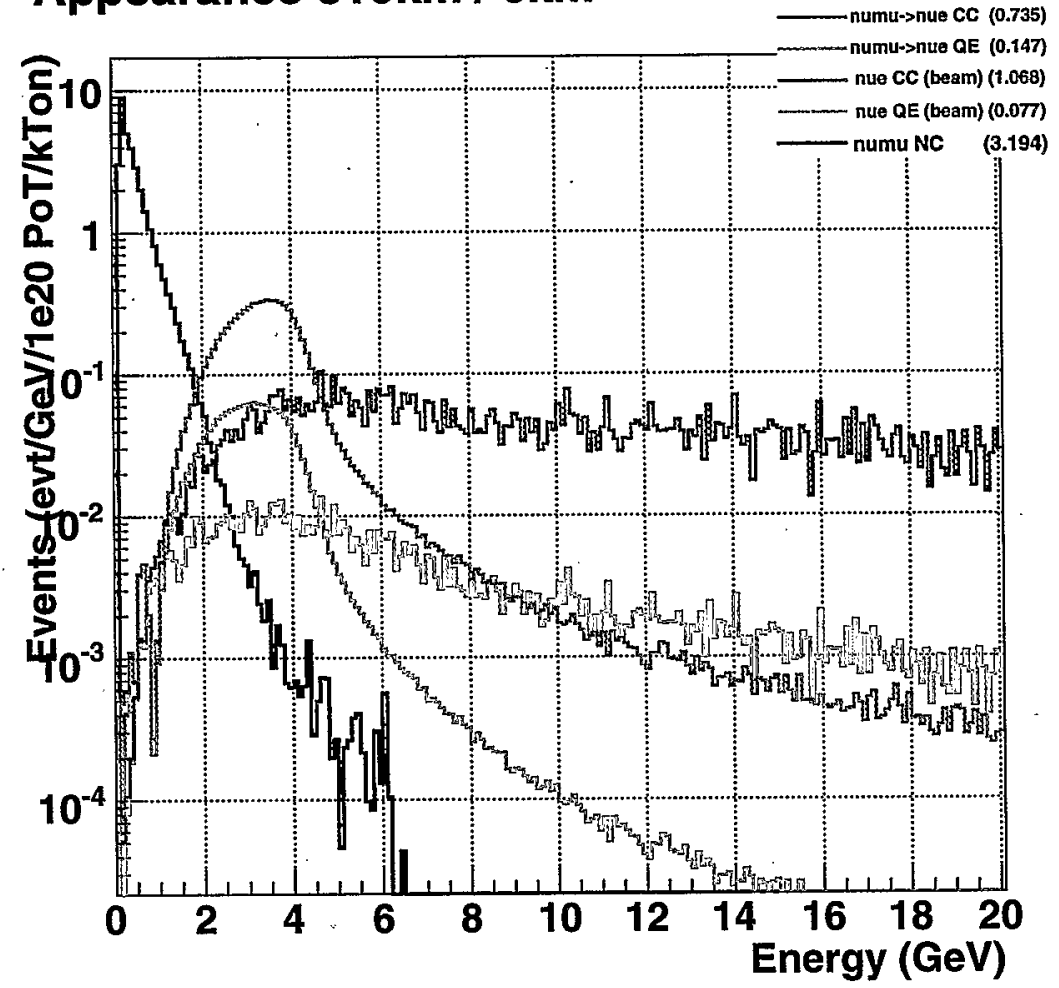

Figure 9: Disappearance (left) and appearance (right) for $810 \mathrm{~km}$ baseline and $6 \mathrm{~km}$ off-axis. 


\section{Disappearance $810 \mathrm{~km} / 6 \mathrm{~km}$}

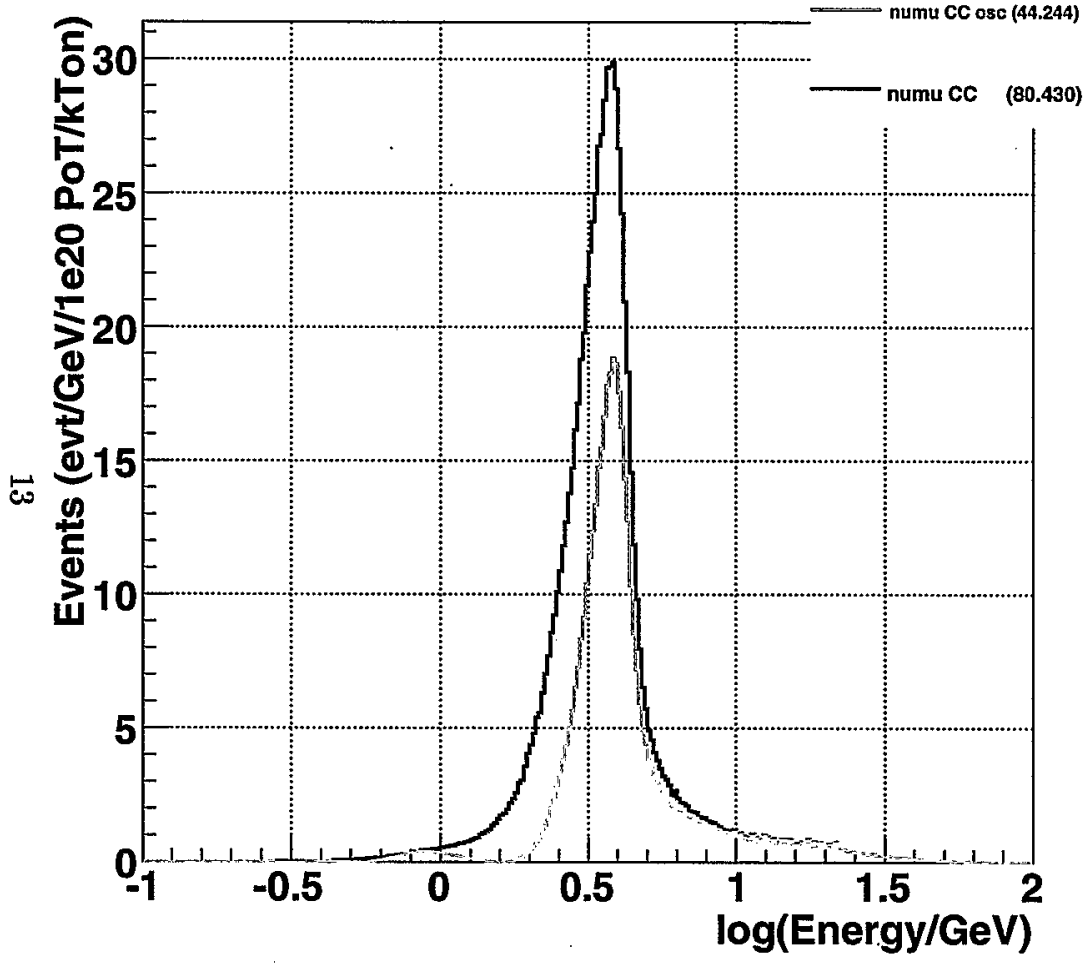

Appearance $810 \mathrm{~km} / 6 \mathrm{~km}$

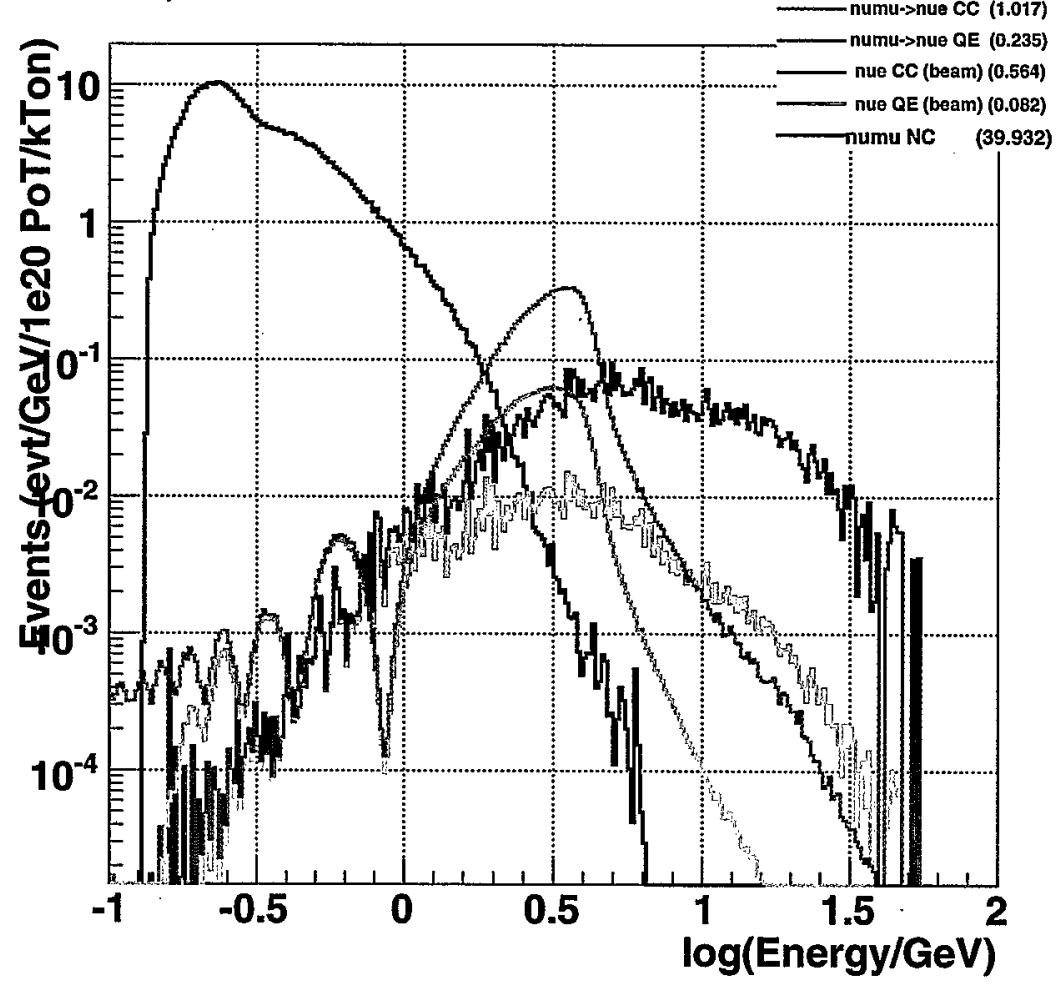

Figure 10: Disappearance (left) and appearance (right) for $810 \mathrm{~km}$ baseline and $6 \mathrm{~km}$ off-axis. 

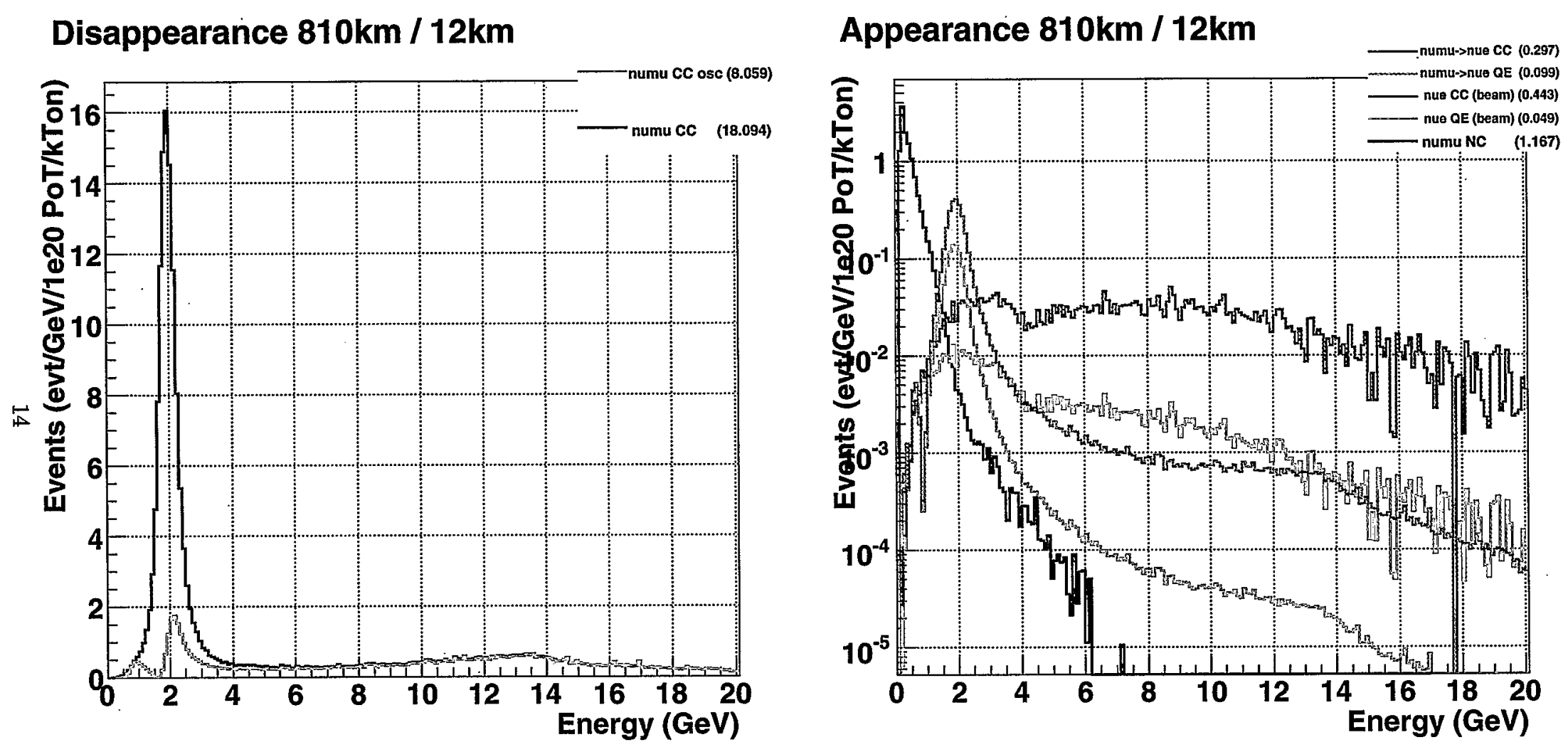

Figure 11: Disappearance (left) and appearance (right) for $810 \mathrm{~km}$ baseline and $12 \mathrm{~km}$ off-axis. 


\section{Disappearance $810 \mathrm{~km} / 12 \mathrm{~km}$}

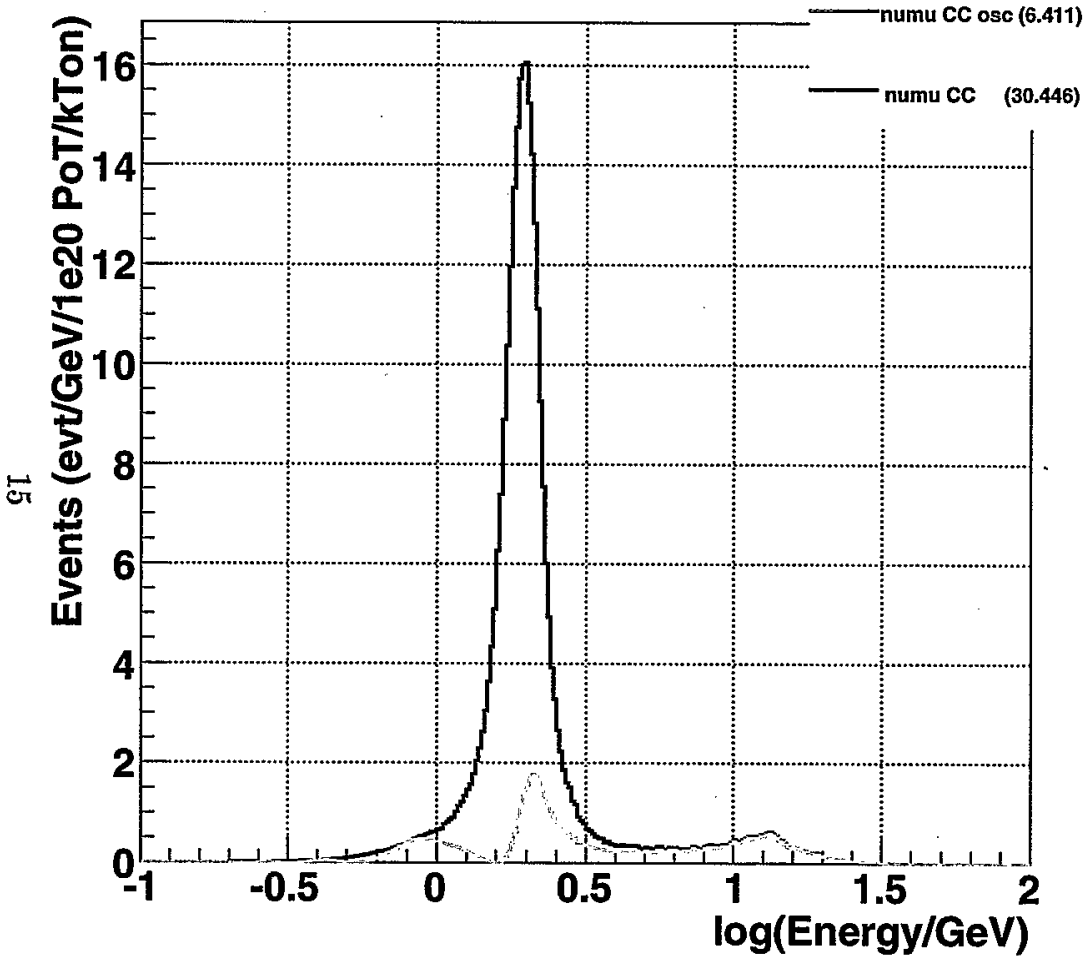

Appearance $810 \mathrm{~km} / 12 \mathrm{~km}$

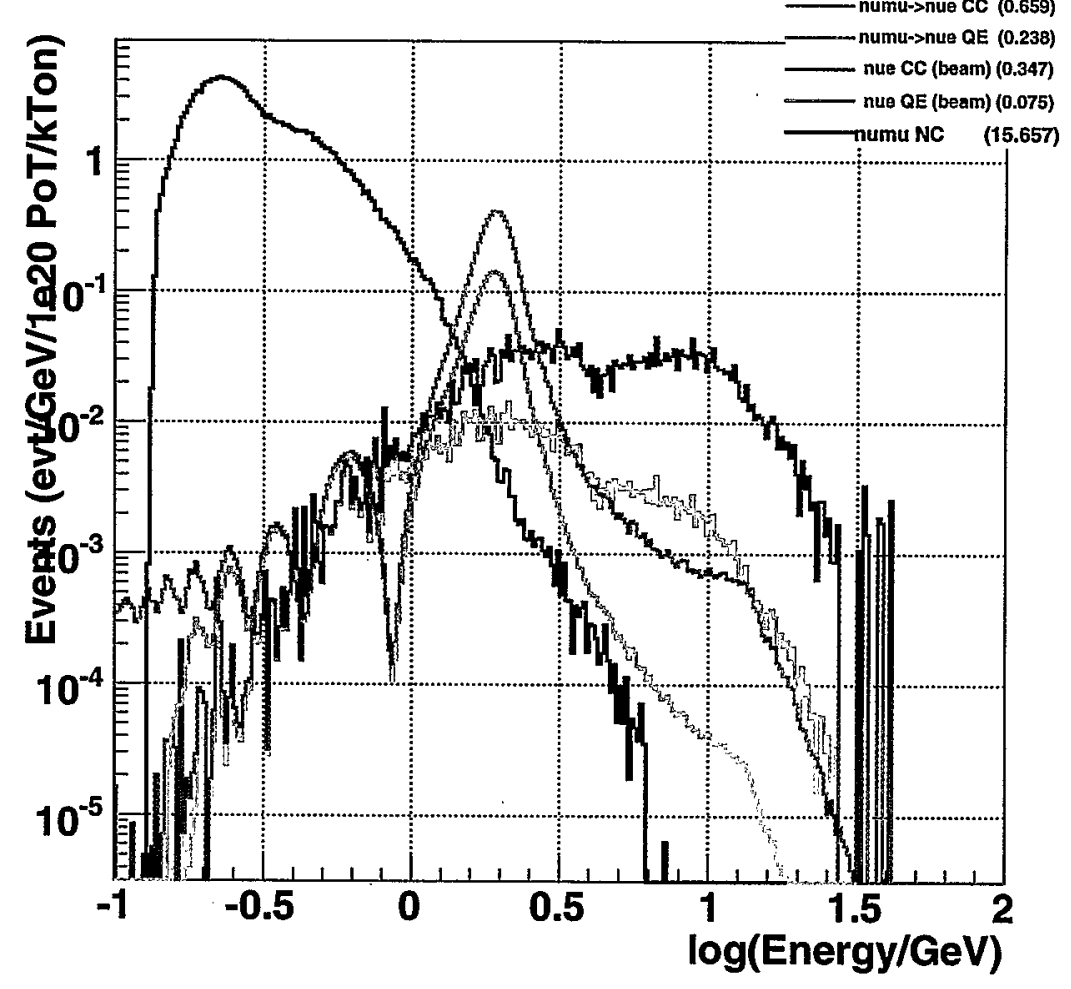

Figure 12: Disappearance (left) and appearance (right) for $810 \mathrm{~km}$ baseline and $12 \mathrm{~km}$ off-axis. 


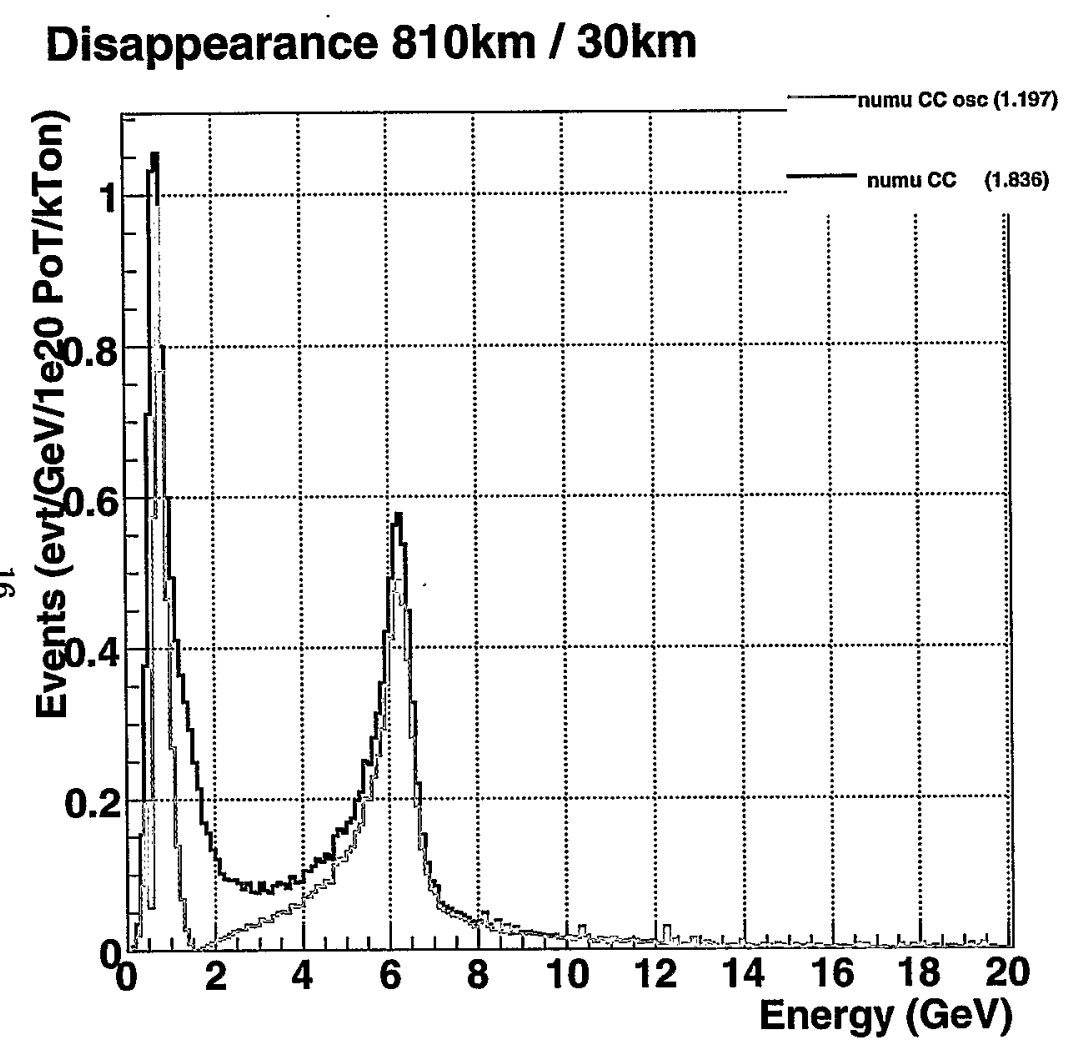

\section{Appearance $810 \mathrm{~km} / 30 \mathrm{~km}$}

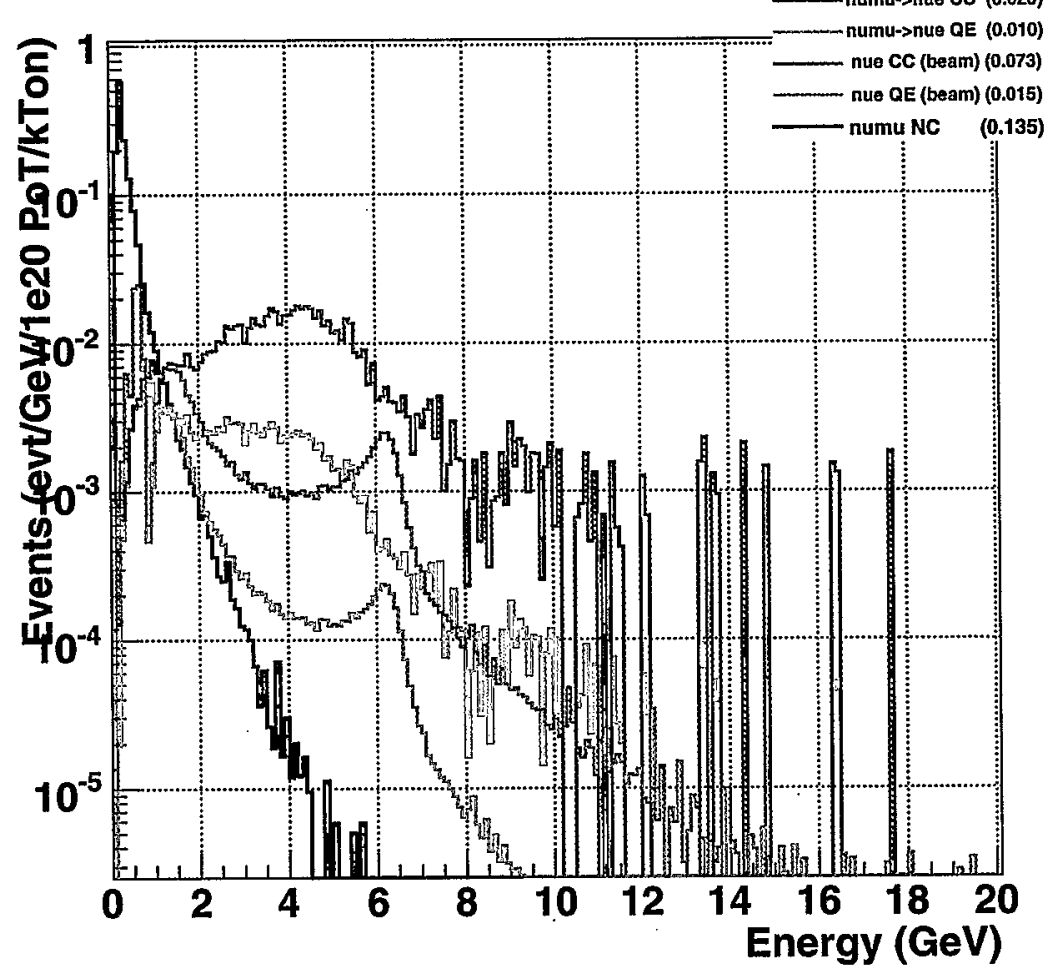

Figure 13: Disappearance (left) and appearance (right) for $810 \mathrm{~km}$ baseline and $30 \mathrm{~km}$ off-axis. 


\section{Disappearance $810 \mathrm{~km} / 30 \mathrm{~km}$}

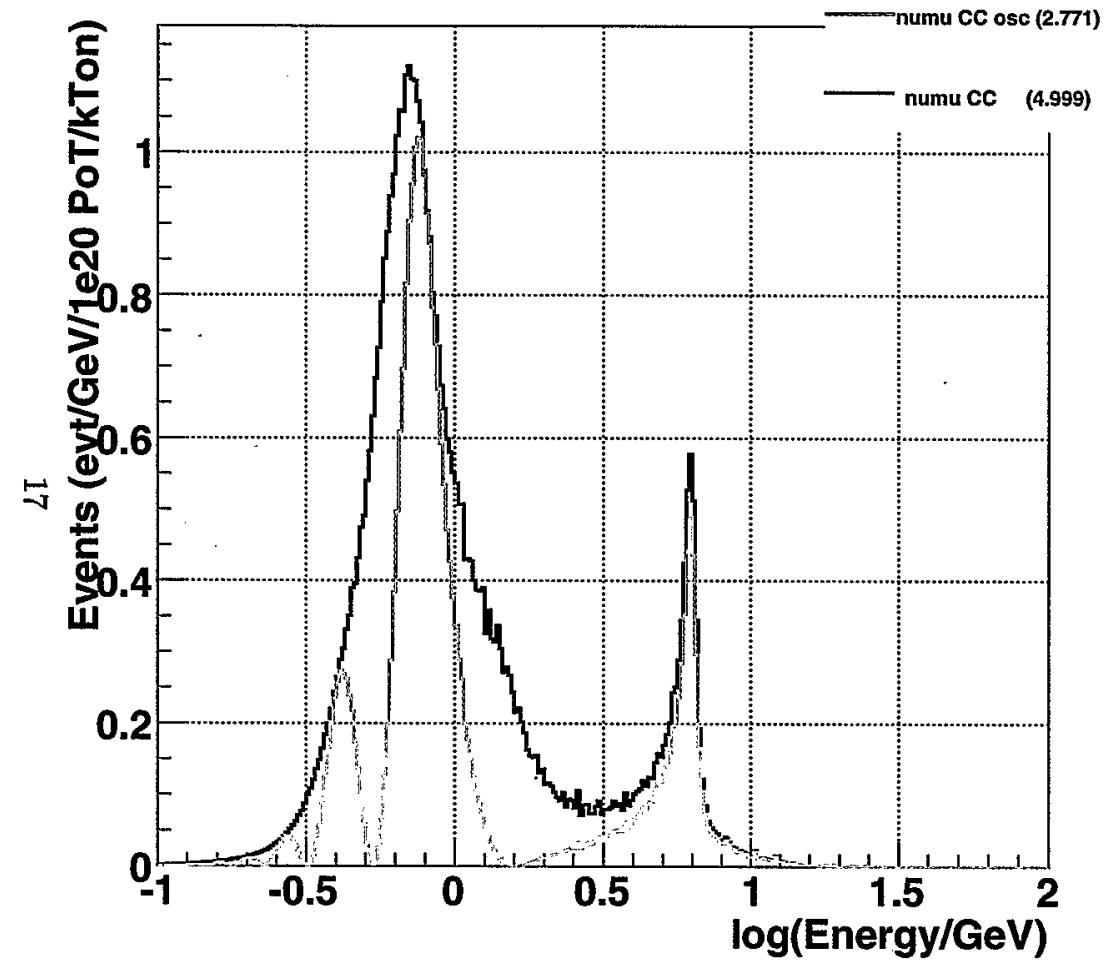

\section{Appearance $810 \mathrm{~km} / 30 \mathrm{~km}$}

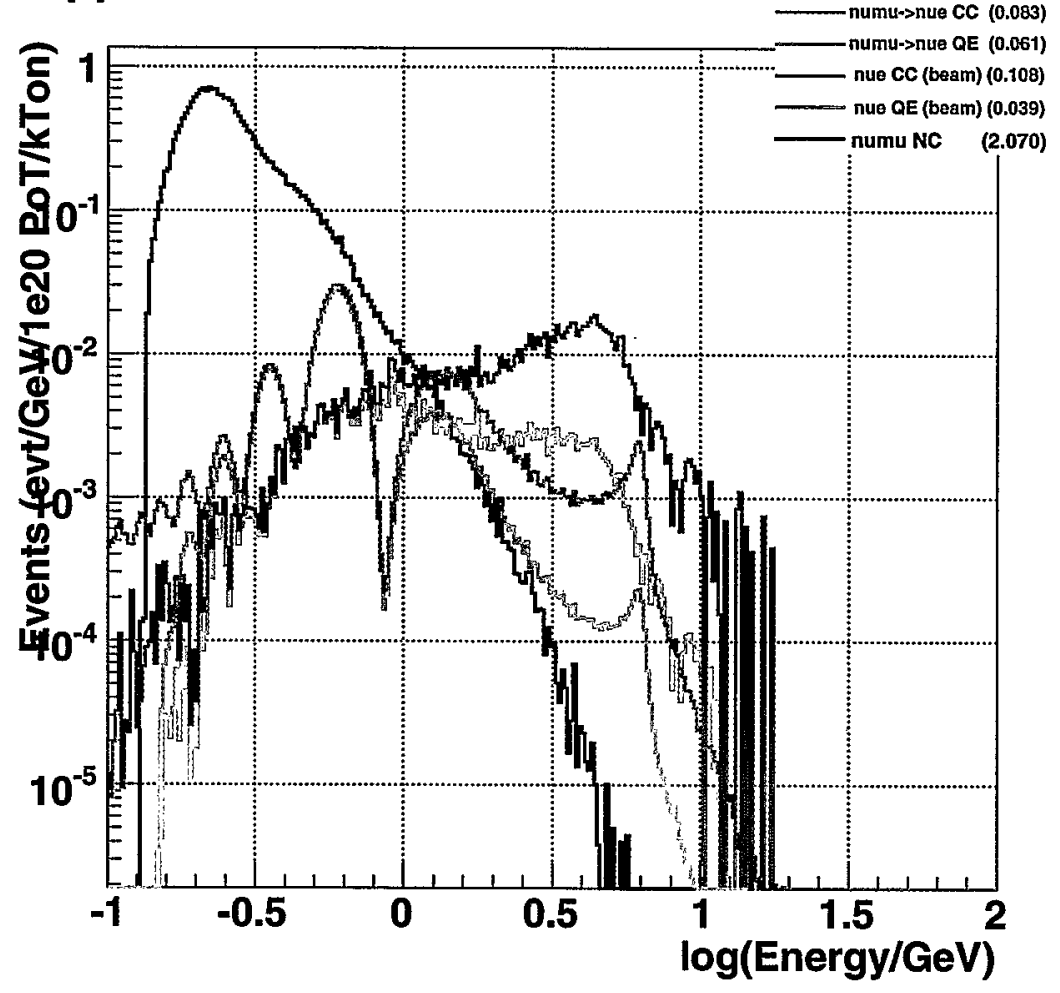

Figure 14: Disappearance (left) and appearance (right) for $810 \mathrm{~km}$ baseline and $30 \mathrm{~km}$ off-axis. 

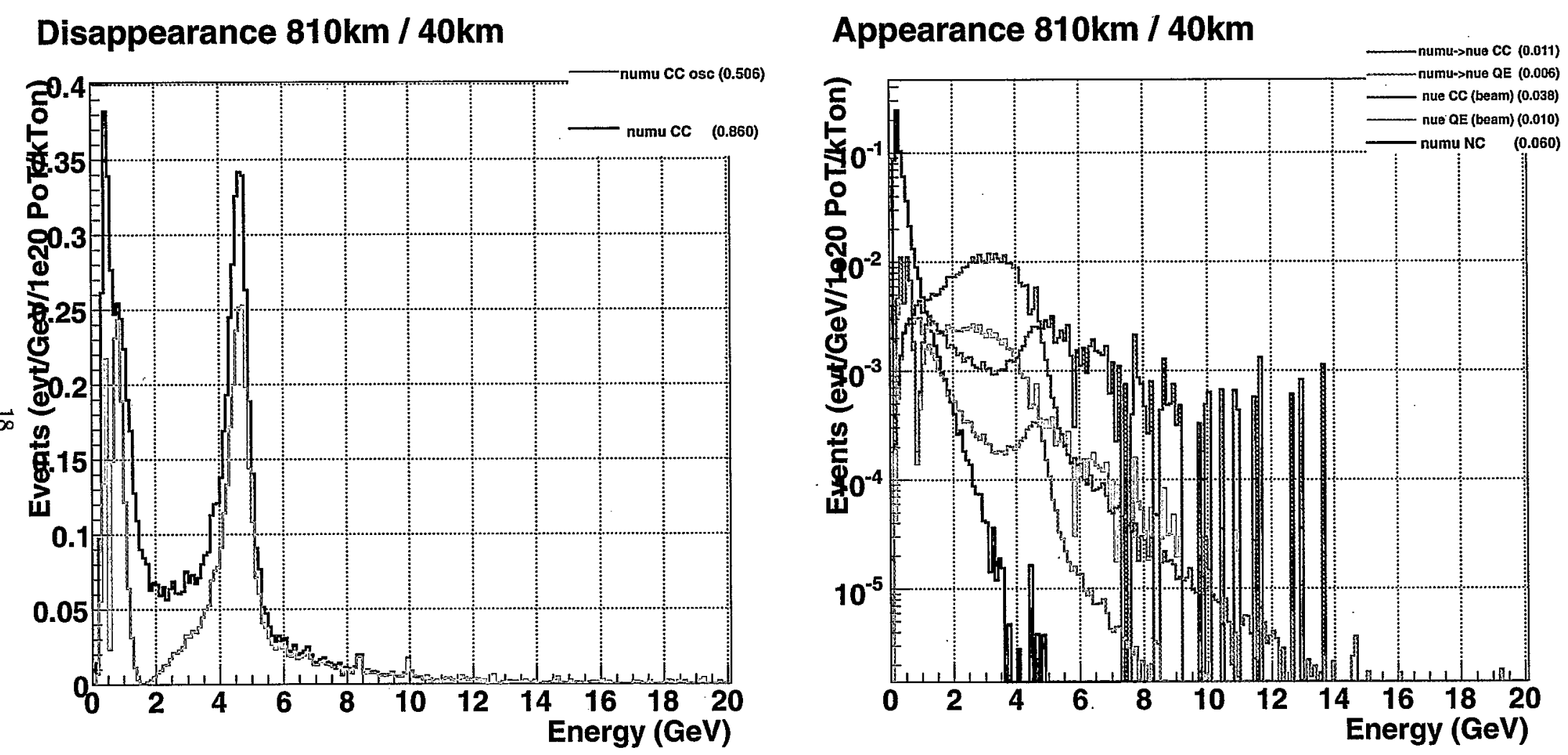

Figure 15: Disappearance (left) and appearance (right) for $810 \mathrm{~km}$ baseline and $40 \mathrm{~km}$ off-axis. 

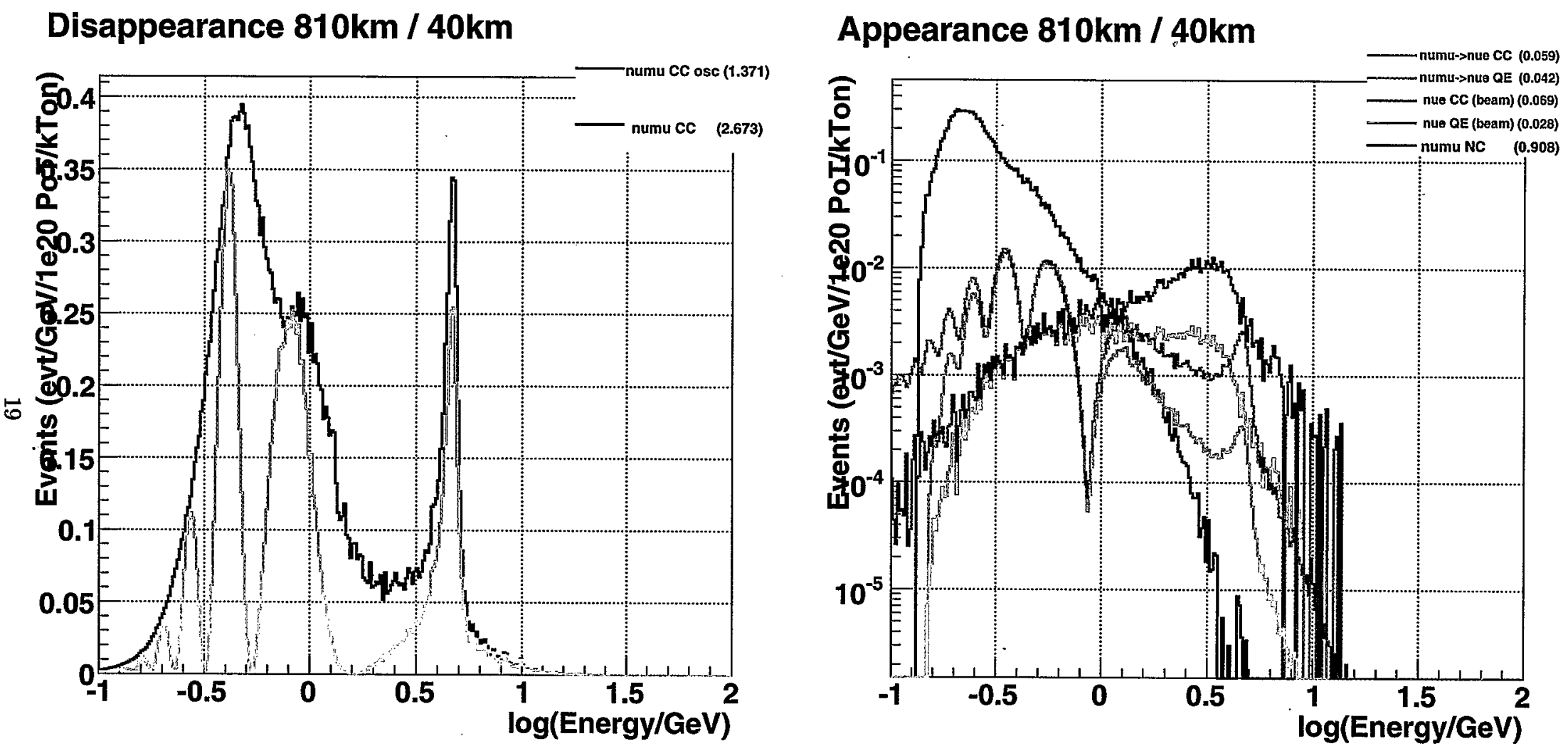

Figure 16: Disappearance (left) and appearance (right) for $810 \mathrm{~km}$ baseline and $40 \mathrm{~km}$ off-axis. 


\section{List of Figures}

1 Flux spectra of $\nu_{\mu}$ neutrinos at $1 \mathrm{~km}$ for the beams considered. Note, this is not far flux scaled to $1 \mathrm{~km}$. It contains effects of the secondary beam being an extended source. . . . . . . 3

2 Neutrino flux spectra at $1 \mathrm{~km}$ for the ME beam. . . . . . . . . . . . . . . 4

3 Disappearance (left) and appearance (right) neutrino oscillation probabilities as a function of the neutrino energy. See table 2 for oscillation parameters. . . . . . . . . . . 5

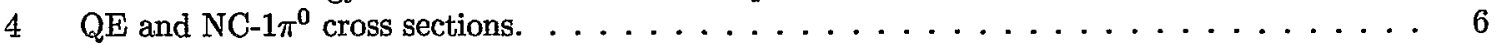

5 (a) $q^{2}$ (top) and (b) $\pi^{0}$ energy (bottom) as functions of mono-energetic neutrinos in $1 \mathrm{GeV}$ steps. Calculation uses $0.5 \mathrm{GeV}$ steps in neutrino energy. . . . . . . . . . . . 7

6 MINOS Near Detector data and GNUMI MC simulation comparison of interaction spectra[4]. From left, LE, pME and pHE beams. Top row shows data spectra as black points, MC as gray shaded region with a width representing $\mathrm{MC}$ uncertainty. Bottom row shows ratio of data to MC. . . . . . . . . . . . . . . . . . . . . 8

7 Disappearance (left) and appearance (right) for $810 \mathrm{~km}$ baseline and $0 \mathrm{~km}$ off-axis. . . . . 10

8 Disappearance (left) and appearance (right) for $810 \mathrm{~km}$ baseline and $0 \mathrm{~km}$ off-axis. . . . . 11

9 Disappearance (left) and appearance (right) for $810 \mathrm{~km}$ baseline and $6 \mathrm{~km}$ off-axis. . . . . . 12

10 Disappearance (left) and appearance (right) for $810 \mathrm{~km}$ baseline and $6 \mathrm{~km}$ off-axis. . . . . 13

11 Disappearance (left) and appearance (right) for $810 \mathrm{~km}$ baseline and $12 \mathrm{~km}$ off-axis. . . . . 14

12 Disappearance (left) and appearance (right) for $810 \mathrm{~km}$ baseline and $12 \mathrm{~km}$ off-axis. . . . . 15

13 Disappearance (left) and appearance (right) for $810 \mathrm{~km}$ baseline and $30 \mathrm{~km}$ off-axis. . . . . 16

14 Disappearance (left) and appearance (right) for $810 \mathrm{~km}$ baseline and $30 \mathrm{~km}$ off-axis. . . . . 17

15 Disappearance (left) and appearance (right) for $810 \mathrm{~km}$ baseline and $40 \mathrm{~km}$ off-axis. . . . . 18

16 Disappearance (left) and appearance (right) for $810 \mathrm{~km}$ baseline and $40 \mathrm{~km}$ off-axis. . . . . 19

\section{List of Tables}

1 Summary of Neutrino Flux Spectra. Distances are measured w.r.t. face of horn 1. . . . . 2

2 Neutrino oscillation parameters used in this study. . . . . . . . . . . . . 3

3 Summary of event rates per-kTon per- $10^{20}$ PoT for detectors placed $810 \mathrm{~km}$ from the target

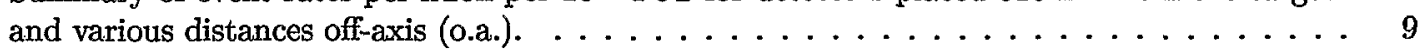

\section{References}

[1] "libnuosc++ - A library for calculating 3 neutrino oscillation probabilities.", B. Viren, http://nwg.phy.bnl.gov/ bviren/elbo/libnuosc++/README.

[2] A. M. Dziewonski and D. L. Anderson, "Preliminary Reference Earth Model," Phys. Earth Planet. Interiors 25, 297 (1981).

[3] D. Casper, Nucl. Phys. Proc. Suppl. 112, 161 (2002), hep-ph/0208030.

[4] "Joint Experimental/Theoretical Physics (Wine and Cheese) Seminar", Fermilab 2006 March 30, D. Petyt for the MINOS Collaboration 